\title{
Analysis of occupational safety measures at work under working conditions at height in temporary and mobile sites
}

\author{
Cristina Gogelescu ${ }^{1}$, Eugenia Tudose ${ }^{1}$, Costinel Bulboacă ${ }^{1}$, Oana Chivu ${ }^{1}$ \\ ${ }^{1}$ University Politehnica of Bucharest, Bucharest, Romania \\ E-mail:cristinameita@gmail.com, jenibulboaca@gmail.com, costinelbulboaca@gmail.com, \\ oana.virlan@upb.ro
}

\begin{abstract}
This work provides an analysis of the identification and assessment of occupational hazards in construction activities from the design phase, setting priorities and measures for prevention and protection. The analysis is structured on the evaluation method, the requirements and regulations in the field and the prevention and protection table. Tables and images on the evaluation stages, how to approach the proposals and how to prioritize prevention and protection measures, requirements, and proposed solutions for the use of specific means of production for working at height are presented. The authors' conclusions present the importance and usefulness of the proposals on the continuous improvement of the level of safety at work for activities that involve working at height according to good practices and current legislation.

Keywords: risk, severity, probability, prevention and protection, work at height
\end{abstract}

\section{Introduction}

For activities that include work at height in the field of construction, the risks to which workers working at height and those to which workers are exposed are exposed are further identified, assessed, and assessed in addition to the occupational risks specific to the work on site.

The risk management activity shall assess the risks associated with each type of work at height and determine the monitoring and control measures necessary to ensure that the activity and those in the surrounding areas can be carried out safely.

\section{Risk identification and assessment [3]}

Organizations identify and assess risks from the design phase of the project.

The risk assessment method consists of several steps:

- identification of the main foreseeable risk factors of the work system;

- establishing the consequences of the action on the executant, including their gravity;

- establishing the probability of action of the risk factors on the executant;

- determining the level of priority depending on the severity and probability of the consequences

- risk factors;

- elaboration of prevention and protection measures. 
The assessment of occupational injury risks involves the following steps:

Stage I - Systemic analysis of the activities identified at the jobs according to the four elements of the work system:

Executant - the person directly involved in the execution of a work task.

The medical and employment control, the professional qualification necessary for the activity they carry out, the training on health and safety at work in compliance with the mandatory stages, the existence of the identification card of the professional risk factors to which the executant is exposed are taken into account.

Means of production - the totality of labor, technical equipment, labor objects, raw materials, materials, etc., which are used in the labor process. It takes into account the use of technical equipment in the parameters provided by the technical book, the maintenance of the safety and protection devices with which the technical equipment was equipped, the periodic inspection of appliances, industrial machines, safety components and safety devices. and protection, compliance, according to the technical book of technical equipment, technical revisions, current and major repairs.

Work task - the totality of actions that must be performed through the means of production and under certain environmental conditions by the executant, in order to carry out the work process.

It is considered the clear definition of the workload and the information on the possible risks to which the worker is exposed, the endowment with individual protective equipment corresponding to the workload risks, the observance of the regulations regarding the technical-organizational measures to avoid or reduce the risks of injury and/or impairment of health caused by the organization of working time and rest, physical exertion (including the activity of women and young people), mental exertion.

Work environment - the set of physical, chemical, biological or psychological conditions in which one or more performers perform their work task. It is considered the verification of the existence of the bulletins for determining the pollutants according to the regulations, the observance of the regulations regarding the organization of the workplaces taking into account the ensuring of the microclimate, lighting and adequate ventilation, maintaining in the normal parameters, the influence of chemical and biological agents, carcinogens and mutagens, other environmental conditions.

Stage II - Determining the risks of accidents or occupational diseases at the identified workplaces:

The basis of the risk assessment principle is to take into account two parameters:

- probability of manifestation of the risk (occurrence of the event)

- the severity of the maximum foreseeable consequence.

The elements of risk are presented in Table no. 1.

The severity (severity of possible damage) can be estimated taking into account the nature of what needs to be protected (people, property, environment), severity of injury or damage to health (mild normally reversible, severe - normally irreversible, death), extent damage (one person, several people).

The severity of the consequences of the impact on the executant falls into 4 severity classes:

1 - low: accident without interruption of activity that does not involve medical leave;

2 - average: accident involving the interruption of activity and granting medical leave for temporary incapacity for work;

3 - serious: accident that results in permanent incapacity for work;

4 - very serious: death. 
Table no. 1 Elements of risk

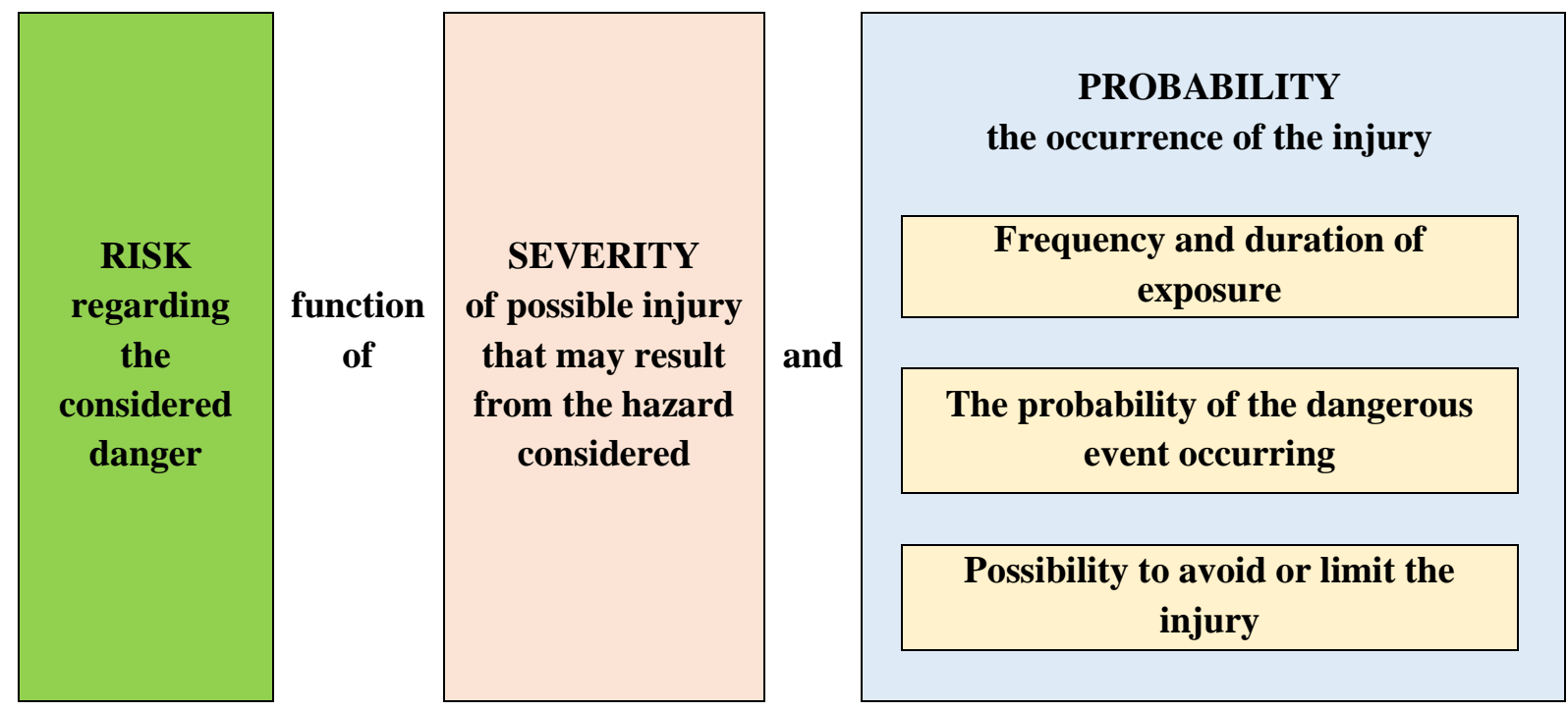

In assessing the risk of injury, the maximum foreseeable severity is taken into account.

The scale of the severity of the consequences is based on medical criteria for clinical diagnosis, function, and assessment of work capacity.

When establishing the probability of the risk action, the number of exposed persons, the number of accidents or occupational diseases registered in a determined period, as well as the degree of technicality of the evaluated workplace (activity) are considered.

The probability scale of the occurrence of the maximum foreseeable consequence is determined according to the scheme in Table no. 2.

Table no. 2 Estimating the probability of injury

\begin{tabular}{|c|c|c|}
\hline $\begin{array}{c}\text { Frequency and / or } \\
\text { duration of exposure }\end{array}$ & $\begin{array}{c}\text { Probability of occurrence of the } \\
\text { triggering event }\end{array}$ & Probability of injury \\
\hline \multirow{2}{*}{ rare } & low & Very unlikely \\
\cline { 2 - 3 } & high & improbable \\
\hline \multirow{2}{*}{ frequent } & low & probable \\
\cline { 2 - 3 } & high & Very probable \\
\hline
\end{tabular}

The probability class is from 1 (extremely rare consequences - very unlikely) to 4 (very common very unlikely).

The probability of injury can be estimated taking into account:

- frequency and duration of exposure, which depend on the need for access to the hazardous area (eg. for normal operation, maintenance or repairs), the nature of access (eg. manual supply of materials), time spent in the hazardous area, number of persons accessing, frequency of access.

- the probability of occurrence of the dangerous event, which depends on the reliability and other statistical data, the history of the accident, the history of health damage, the comparison of risks. 
- the possibilities of avoiding or limiting the damage, which depend on the people using the car (their qualification, the lack of a driver), the speed of occurrence of the dangerous event (sudden, fast, slow), any form of risk awareness (through general information, by direct observation, by means of warning signals and indicating devices), human possibilities to avoid or limit damage (possible, possible under certain conditions, impossible), practical experience and knowledge (relating to the machine, to a similar machine or without the experience).

\section{Stage III - Determining the priority level of actions}

The determination of the priority level of the actions is made according to the probability of manifestation of the risk (occurrence of the event) and the severity of the maximum foreseeable consequence

The risk assessment grid is a matrix with 4 rows and 4 columns representing the classes of probability of occurrence of the maximum predictable consequences and the severity of the consequences.

At the intersection of the probability probability class (exposure frequency) with the severity class, the priority level of the actions results $-1,2,3$ or 4 .

Priority 1 - for risks to be treated with priority;

Priority 2 - for risks to be addressed as soon as possible;

Priority 3 - for risks that can be treated later;

Priority 4 - for risks that can be treated later;

\section{Stage IV - Preparation of the Prevention and Protection Table on the job}

The elaboration of the Table of prevention and protection on the job is done by filling in the headings of Table no. 3 .

Table no.3 Establishing the level of priority for prevention and protection measures

\begin{tabular}{|c|c|c|c|c|c|c|c|}
\hline \multicolumn{2}{|c|}{$\begin{array}{c}\text { Exposure frequency / } \\
\text { Probability }\end{array}$} & \multirow{2}{*}{$\begin{array}{c}\begin{array}{c}\text { Exposure } \\
\text { level }\end{array} \\
4\end{array}$} & \multicolumn{2}{|c|}{ Gravity } & \multirow{2}{*}{$\begin{array}{c}\text { Gravity } \\
\text { level }\end{array}$} & \multirow{2}{*}{$\begin{array}{c}\begin{array}{c}\text { Prevention and } \\
\text { protection } \\
\text { measures } \\
\text { priority }\end{array} \\
\text { P1 }\end{array}$} & \multirow{2}{*}{$\begin{array}{r}\text { Risk } \\
\text { level }\end{array}$} \\
\hline $\begin{array}{l}\text { Very } \\
\text { high }\end{array}$ & 1/ week & & $\begin{array}{l}\text { Very } \\
\text { serious }\end{array}$ & death & & & \\
\hline high & $1 /$ month & 3 & serious & $>90$ days & 3 & $\mathrm{P} 2$ & 3 \\
\hline average & 1/year & 2 & average & $\begin{array}{c}\text { ITM } \\
\text { (temporary } \\
\text { incapacity for } \\
\text { work) } \\
7 \text { - } 90 \text { days }\end{array}$ & 2 & P3 & 2 \\
\hline low & $>1 /$ year & 1 & low & $\begin{array}{c}\text { ITM } \\
\text { (temporary } \\
\text { incapacity for } \\
\text { work) } \\
3-6 \text { days }\end{array}$ & 1 & P4 & 1 \\
\hline
\end{tabular}

For the description of the job, a concrete and detailed description of the activity performed by the executant at the job will be made. 
It will be specified, as the case may be, particulars regarding:

- executant (gender / gender, membership of sensitive risk groups, apprenticeship, or probationary period, etc.)

- work task (all operations will be listed, in the order given by the technological process, that the executant must perform)

- means of production (means of work, objects of work, related means of work) used by the executant to carry out operations: mode of operation (manual, electric, hydraulic, pneumatic) and, where appropriate, if it is part of a technological line, including neighborhoods with other jobs, etc.

- work environment: internal (microclimate (temperature, humidity, air pressure, air currents, dust), noise, lighting, vibration, radiation, electrostatic potential, etc. in the context of the workplace location on site) and external (neighborhoods, social, economic, other)

The findings regarding the activities, their analysis and the existing and proposed prevention and protection measures will be completed in Table no. 4 Prevention and protection table

Table no. 4 Prevention and protection chart model

\begin{tabular}{|c|c|c|c|c|c|c|c|c|}
\hline No. & $\begin{array}{c}\text { System } \\
\text { the work structure }\end{array}$ & $\begin{array}{c}\text { Specific } \\
\text { risk } \\
\text { factors }\end{array}$ & $\begin{array}{c}\text { Presentation } \\
\text { possible } \\
\text { situation } \\
\text { injury / } \\
\text { disease } \\
\text { professional }\end{array}$ & \multicolumn{2}{|c|}{$\begin{array}{c}\text { Gravity level } \\
(\mathbf{G}) \text {, probability } \\
\text { (P), risk (R) }\end{array}$} & $\begin{array}{c}\text { Measures } \\
\text { of } \\
\text { existing } \\
\text { prevention } \\
\text { and } \\
\text { protection }\end{array}$ & $\begin{array}{c}\text { Measures } \\
\text { of } \\
\text { prevention } \\
\text { and } \\
\text { protection } \\
\text { proposals }\end{array}$ \\
\hline 1 & Executant & & & & & & & \\
\hline 2 & Work task & & & & & & & \\
\hline 3 & Means of production & & & & & & & \\
\hline 4 & Work environment & & & & & & & \\
\hline
\end{tabular}

Stage V - Development of prevention and protection measures, other than existing ones

When drawing up the prevention and protection table, the recommendations from Table no. 5.

Table no.5 Approach for proposing prevention and protection measures other than existing ones

\section{PRIMARY MEASURES}

Elimination of risks

For the identified hazardous situation, measures are proposed to act immediately and directly on the hazard to eliminate it.

\section{SECONDARY MEASURES}

The dangerous situation cannot be eliminated directly, but the proposed

Risk isolation preventive measures for collective protection prevent or reduce the executor's exposure to danger.

Providing physical protections / locks

\section{TERTIARY MEASURES}

Avoid of risks

The points of interaction between the performer and the risk factors are avoided by prevention and protection measures regarding:

- organizing the activity at the workplace; 
Thoth Publishing House

\begin{tabular}{|c|l|}
\hline & $\begin{array}{l}\text { - instructions on changing the behavior of the executor; } \\
\text { - awareness of the executor regarding the exposure to the risks } \\
\text { identified in the workplace; }\end{array}$ \\
\hline \multicolumn{2}{|c|}{ QUATERNARY MEASURES } \\
\hline $\begin{array}{c}\text { Isolation } \\
\text { executant }\end{array}$ & $\begin{array}{l}\text { Protecting the executor by limiting the action of risk factors using } \\
\text { means and equipment of personal protection }\end{array}$ \\
\hline
\end{tabular}

Prevention and protection measures must meet a number of requirements whereby:

- to eliminate, reduce or limit the risks;

- not to transfer the risks;

- the prevention measure adopted is stable over time;

- to be able to generate the measure in other similar situations;

- not to create a mental overload for the human operator, due to the adoption of the measure;

- to consider the deadlines;

- to calculate the cost / benefit ratio of the measure;

- to ensure the compliance of the measure with the regulations in force.

This information should not be a substitute for the correct application of intrinsic prevention and protection measures, collective or individual protection measures, and complementary prevention measures.

When choosing prevention measures, the judicious application of the general principles of prevention must be considered.

\section{Current situation}

Minimum occupational safety requirements to be met when performing work at height:

- the employment and distribution of workers for working at height is ensured on the basis of the medical approval issued following a medical examination through which the skills and neuropsychic capacities necessary for working at height must be verified;

- all workers working at height are checked periodically by medical examination (periodicity and clinical - functional examinations are established by the Ministry of Health according to the characteristics of the workplace);

- persons under 18 years of age are not allowed to work at height;

- for the execution of works at height, the prior technological organization of works at height must be taken into account by achieving all the conditions for ensuring collective protections, depending on the specifics of the workplace, for the entire duration of the works, endowment with individual equipment protection in accordance with the concrete risks of the workplace, the obligation to train and use the collective and individual endowments corresponding to the specific risks of the workplace and the respective works.

Hierarchy of prevention and protection measures:

- elimination - elimination of the need to work at height (bringing the work to ground level);

- substitution (isolation) - use of physical barriers to fence an area (platform and fixed railings);

- engineering (security design) - use of temporary platforms to access the work area (raised mobile platform, scaffolding);

- administrative (organizational) and personal protective equipment - organization and use of risk assessments, safe working practices, permits, training and protections, equipment and systems to restrict and stop the fall. 
In addition, warnings and all notifications are important means of supporting and ensuring the effectiveness of each level of the control hierarchy. This is done by using signals, information, training and other forms of communication to restrict access and prevent falls. [2]

A model of hierarchy of measures for working at height is presented in Table no. 6

Table no. 6 Model of hierarchy of measures for work at height

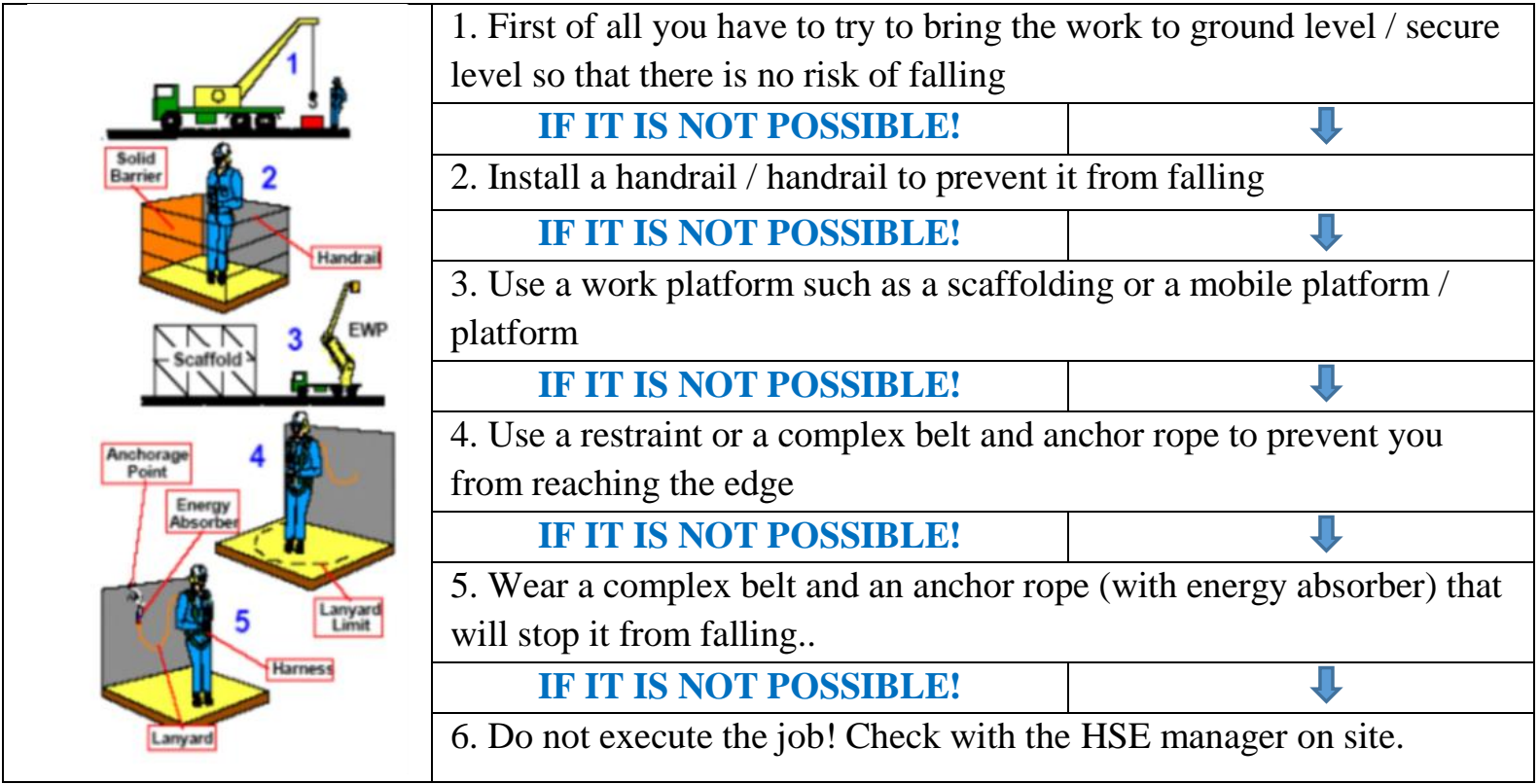

If removal is not possible, work at height is carried out, if possible, on a fixed platform with appropriate deck, anchors, and railings.

Fixed platforms include permanently raised walkways or permanent work areas.

The construction and use of fixed platforms and access equipment (stairs and fixed steps) is carried out in accordance with the specific regulations in force.

When removal is not possible, work at height shall be carried out on a fixed platform with appropriate deck and railings.

Fixed platforms include walkways or permanently mounted work areas.

Mobile lifting platforms are designed to provide a temporary work platform that can be easily moved from one location to another.

When working on the platform it is mandatory to wear protective equipment - fall arrest system.

An ISCIR (State Inspection for the Control of Boilers, Pressure Vessels and Lifting Installations) authorization is required for the operation of mobile lifting platforms.

The platform operator must be authorized and periodically tested RSVTI (Responsible for the supervision and technical verification of the installations) with its own or external personnel. 

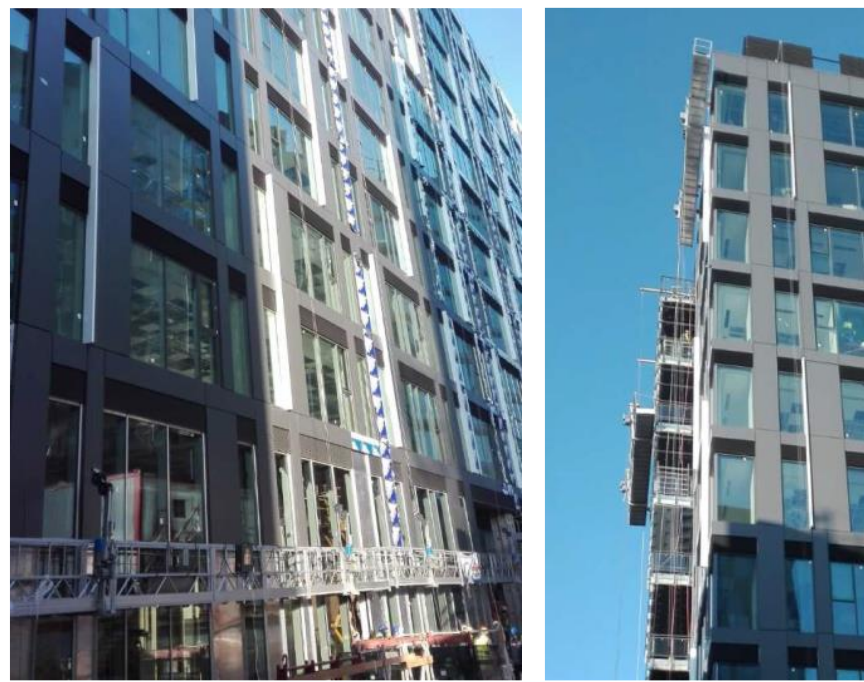

Figure no. 1 - Images of Bridge III site platforms

Escalators are used only for access and for a short time, in accordance with local regulations and manufacturer's specifications, shown in Figure no. 1

Escalators are only used for access and for short-term tasks, in accordance with specific regulations in force, manufacturer's specifications and safe working practices.

Escalators are not used as a work platform if there is a reasonable alternative (e.g. tower or elevator scaffolding).

All escalators must be secured against slipping, tied at the top or if this is not possible by securing the sides of the legs or "anchoring the feet".

Stairs must always have a secure base and must never be supported on fixed stairs.

The correct position for the escalators are highlighted in figures no. 2,3,4

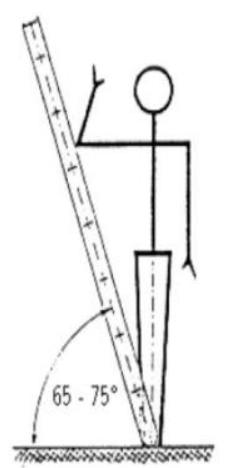

Figure no. 2 Ladder angle

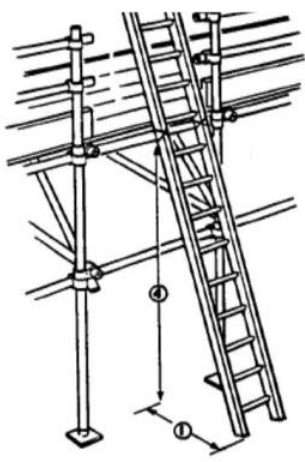

Figure no. 3 Scale positioning

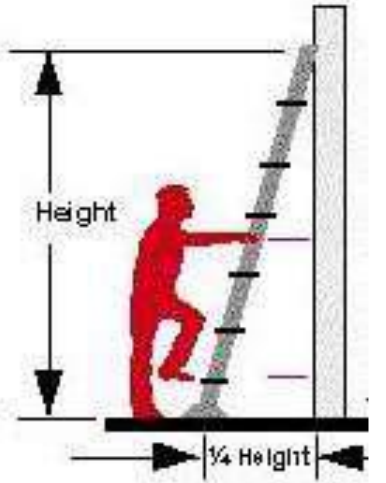

Figure no. 4 Positioning report

Safety fittings are provided for vertical fixed stairs. The fittings are mounted from a height of $2.5 \mathrm{~m}$ above the base of the ladder.

All types of ladders must be labeled before use and checked weekly, as shown in Figure 5. 


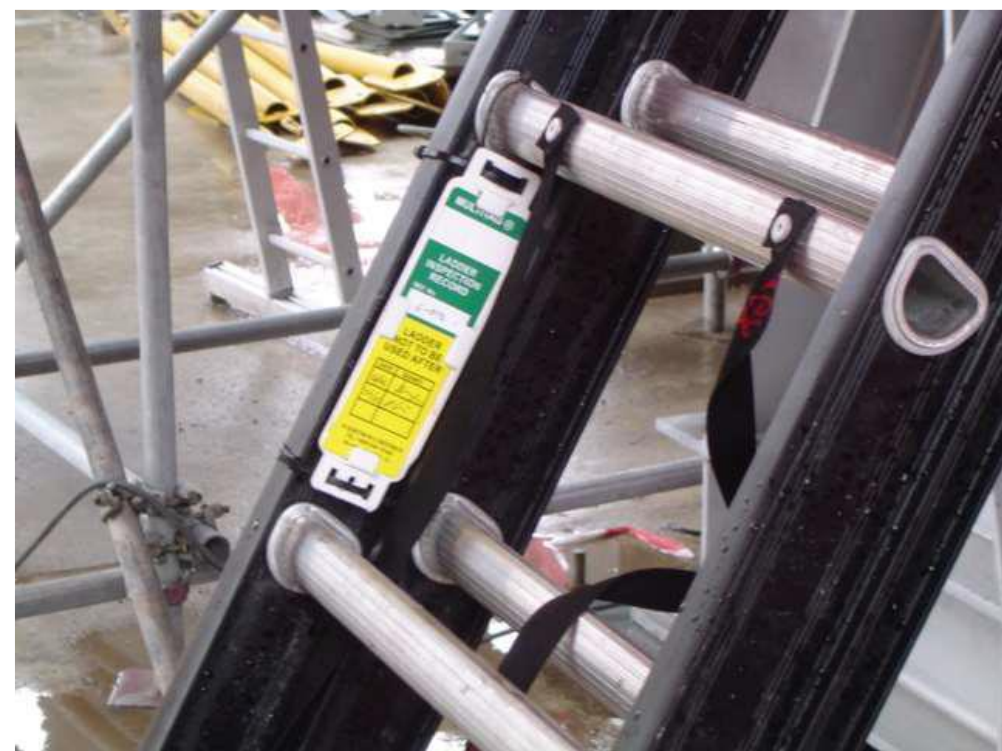

Figure no. 5 Scaffold labeling template

Stairs that can be used safely will be marked with a green label.

Fall restraint and stop systems are used when other control methods (removal or isolation) are not possible.

Workers who need to work at a height above an opening or an unprotected edge from which they may fall (roofs, edge of the top plate, etc.) should use fall restraint equipment such as a fixed anchor and belt. complex, which prevents them from reaching the edge of the opening.

At each site, the procedures for the proper use, inspection and maintenance of fall restraint and stopping equipment shall be updated and verified at least once a year.

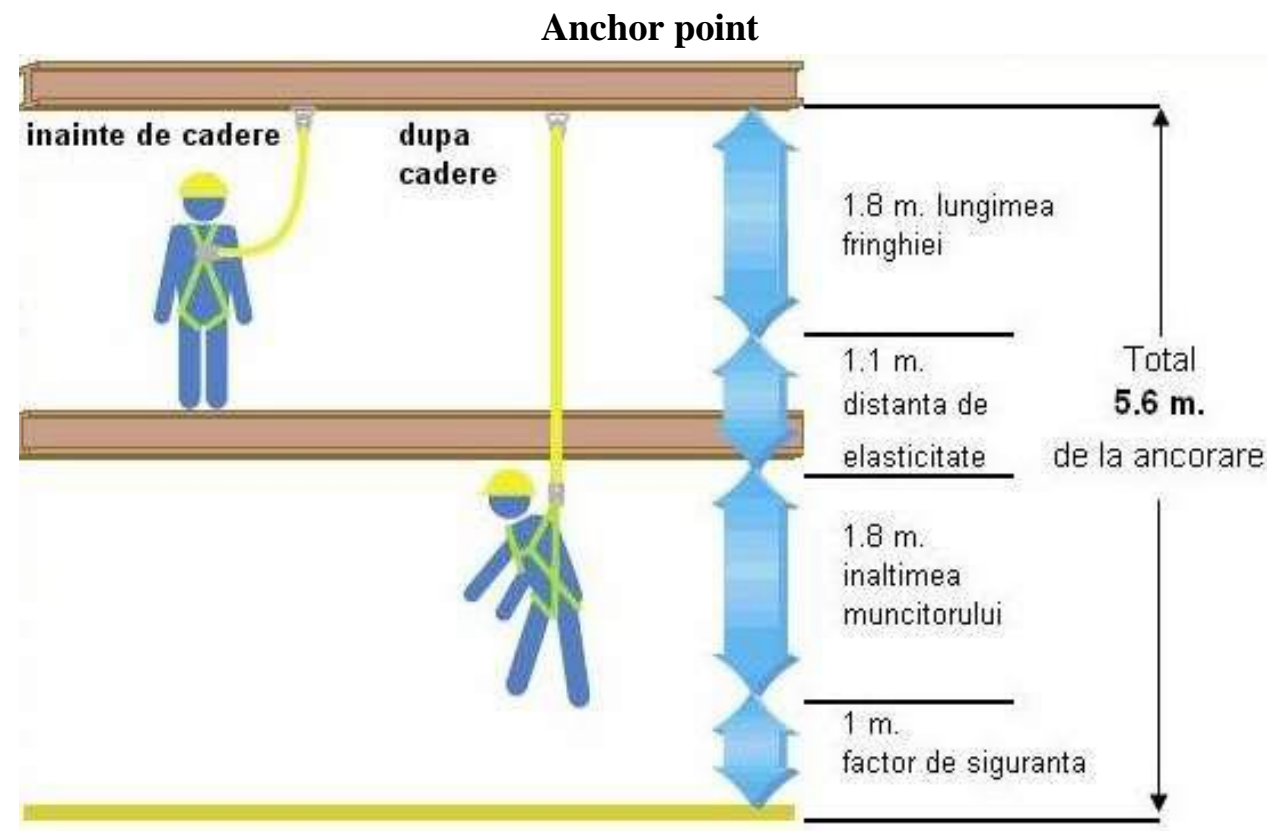

Figure no. 6 Calculation of anchorage distance 


\section{Conclusions}

Following the analysis, the following aspects can be mentioned:

- it is necessary to inform workers about the identification, assessment, and assessment of occupational risks from the design phase of works that involve work at height, the establishment of appropriate prevention and protection measures

- ensuring adequate means of production (platforms, platforms, scaffolding) and safe collective protections

- provision of personal protective equipment for working at height (complex belt, fall arrest, attenuator, safety rope) and verification of its certification, selection, use, maintenance

- drawing up the proposed prevention and protection table

- adapting and implementing legal requirements, standards, good practices, safety and health coordination to workplace prevention and protection measures

\section{References}

[1] *** - Law on Safety and Health at Work no. 319/2006;

[2] Standard Lafarge - Work at Height

[3] Prevention Method - Priorities applied by the Pension House Division for the Prevention of Occupational Diseases and Accidents at Work., Annex 1, Annex 2 